\title{
Joubert syndrome with Jeune asphyxiating thoracic dystrophy
}

INSERM

\section{Source}

INSERM. (1999). Orphanet: an online rare disease and orphan drug data base. Joubert syndrome with Jeune asphyxiating thoracic dystrophy. ORPHA:397715

Joubert syndrome with Jeune asphyxiating thoracic dystrophy (IATD) is an extremely rare genetic bone disorder characterized by the classic features of Joubert syndrome (i.e. malformation of the brainstem causing ataxia, hypotonia,cog nitive impairment, and abnormal eyemovements), associated with the skeletal anomalies found in JATD including short-rib dysplasia and narrow thorax causing respiratory failure, short limbs, and metaphyseal changes. 